\title{
A Comparative Study on the Larvicidal Effects of Piper sarmentosum (Kaduk) Leaves Extracts against Aedes aegypti
}

\author{
Amelia Najiha Othman', Nur Farah Suryani Zainudin'1, Uswatun Hasanah Zaidan² \\ and Suhaili Shamsi ${ }^{1 *}$ \\ ${ }^{1}$ Laboratory for Animal Biochemistry and Biotechnology (ABBTech), Department of Biochemistry, \\ Faculty of Biotechnology and Biomolecular Sciences, Universiti Putra Malaysia, 43400 UPM, \\ Serdang, Selangor, Malaysia \\ ${ }^{2}$ Food and Microbiome Technology Laboratory (FAMTech), Department of Biochemistry, \\ Faculty of Biotechnology and Biomolecular Sciences, Universiti Putra Malaysia, 43400 UPM, \\ Serdang, Selangor, Malaysia
}

\begin{abstract}
Excessive use of synthetic larvicide has led to resistant strains of mosquito vectors and adverse ecological concerns globally. Hence, bioactive compounds from the plant have become a promising alternative to synthetic larvicide. Collectively, there is adequate evidence on the larvicidal effect of Piper sarmentosum (Kaduk). However, its leaves extract's larvicidal effects in different solvent systems are still recondite against Aedes aegypti. The present study aims to investigate the larvicidal activity of the leaves extracts of $P$. sarmentosum in methanol (ME), ethyl acetate (EE), dichloromethane (DE) and hexane (HE), towards the larvae of $A$. aegypti, following the laboratory guidelines provided by the World Health Organization (WHO). HE shows a significantly highest larvicidal activity followed by $\mathrm{DE}, \mathrm{EE}$ and $\mathrm{ME}$, with $\mathrm{LC}_{50}$ and $\mathrm{LC}_{90}$ values of 39.04 and 87.84, 62.78 and $134.73,114.70$ and $169.20,156.10$ and $182.10 \mu \mathrm{g} / \mathrm{mL}$, respectively. The HE was also found to contain the highest total phenolic and total flavonoid content (TPC and TFC), with various bioactive compounds at a higher

ARTICLE INFO

Article history:

Received: 13 April 2021

Accepted: 05 August 2021

Published: 18 October 2021

DOI: https://doi.org/10.47836/pjst.29.4.31

E-mail addresses:

amelianajiha66@gmail.com (Amelia Najiha Othman)

farahsuryanii@gmail.com (Nur Farah Suryani Zainudin)

uswatun@upm.edu.my (Uswatun Hasanah Zaidan)

sh_suhaili@upm.edu.my (Suhaili Shamsi)

* Corresponding author percentage that exerts synergistic effects on the significantly improved larvicidal effect of HE compared to other solvent extracts. The morphological observation of $A$. aegypti larvae upon exposure to HE revealed a significant shrinkage of the internal structure of abdominal and siphon segments that indicates the acute toxicity effect of HE. The present study provides scientific-based
\end{abstract}


evidence on the strongest larvicidal effect of $\mathrm{HE}$ from $P$. sarmentosum leaves extract towards $A$. aegypti for further development as a potential alternative for synthetic larvicide.

Keywords: Aedes aegypti, larvicidal activity, leaves extract, phytochemical content, Piper sarmentosum

\section{INTRODUCTION}

The World Health Organization (2021) claimed that the estimation of people at risk of contracting dengue was more than 3.9 billion in over 128 countries, with 96 million cases per year. In Malaysia alone, 88,845 dengue cases were recorded from January to December 2020, while in 2019, 127,407 cases were recorded within the same period. Selangor has recorded the highest number of dengue cases with 43,491 cases and 37 deaths, followed by Johor with 11,389 cases and 42 deaths in the Federal Territories of Kuala Lumpur and Putrajaya with 10,451 cases and seven deaths. Even though statistics show a decrease of $30.3 \%$ of dengue cases from 2019 , the high number of cases recorded is still of concern (Ministry of Health Malaysia, 2020).

Mosquitoes are the primary known disease vectors able to transmit infectious diseases through the sucking of blood from the infected host (humans and animals) into a new host. There are more than 3,000 species of mosquitoes, but the common genera are Aedes, Anopheles, and also Culex. These mosquitoes serve as vector disease agents, including dengue fever, dengue haemorrhagic fever, Chikungunya, lymphatic filariasis, zika and malaria that are endemic and epidemic in many countries (Reiter, 2001).

Numerous approaches have been employed to hinder mosquito development, which largely involves vector control. Thus, vector control is often viewed as crucial. The mosquito larvae populations are usually controlled by the use of organophosphates, insect growth regulators, microbial agents, and residual spraying and insecticide-treated bed nets. While synthetic larvicides have supposedly become an effective means to control the mosquito larvae population, the excessive use of these synthetic larvicides has triggered the spread of resistant strains in the populations, as well as contributing to environmental pollution and mammalian toxicity (Mohiddin et al., 2016, Suratman et al., 2015). As a result, many non-targeted organisms, such as honey bees (Mahmood et al., 2014) and fish (Anadu et al., 1996, Wang et al., 2017), are at risk over the years. Hence, bioactive compounds isolated from the plant secondary metabolites have become potential alternatives to the present synthetic larvicides.

Consequently, this has become the centre of attention for researchers, specifically in screening potential bioactive compounds from botanical resources to produce biolarvicides. Biolarvicides can be an alternative to synthetic pesticides and have been proven to be more eco-friendly and safer for non-targeted organisms (Guleria \& Tiku, 2009). In addition, chemicals derived from botanical sources have been discovered over decades to have a high potential in controlling mosquitoes (Sukumar et al., 1991). 
The piper species are well-known herb species as they possess promising pharmacological activities along with pesticide and larvicidal activities. Genus Piper, the most abundant genera in the Piperaceae family, with 1000-2000 species are distributed worldwide, and over 400 species were recorded from the Malaysian region alone (Salleh et al., 2014). A previous study has reported on the insecticidal properties of Piper sarmentosum (P. sarmentosum), a wild plant usually grown in tropical countries including Malaysia, from the aerial part and root extracts (Hematpoor et al., 2016), but the data that supports the larvicidal effects of $P$. sarmentosum leaves extract against Aedes aegypti (A. aegypti) remain scarce. Furthermore, no published studies directly compare the effects of solvent extraction on $P$. sarmentosum leaves towards its larvicidal activity. Hence, the present study endeavours to evaluate and compare the larvicidal effects of $P$. sarmentasum (Kaduk) leaves extract in different solvents against $A$. aegypti and identify the potential bioactive components of the extract by using gas chromatography-mass spectrometry (GC-MS).

\section{MATERIALS AND METHODS}

\section{Materials}

All chemicals and reagents used were of analytical grade. Methanol, ethyl acetate, dichloromethane, hexane (R\&M Chemicals, United Kingdom) and dimethyl sulfoxide (DMSO) (Merck, Germany) (PP: 99.8\%, AR), Follin Ciocalteu reagent (Merck, Germany), gallic acid (Sigma Aldrich, Germany), quercetin hydrate (Acros Organics, United States), sodium carbonate (Merck, Germany), sodium nitrate (Merck, Germany), aluminium chloride (R\&M Chemicals, United Kingdom), sodium hydroxide (Macron Fine Chemicals, United States), Abate $1.1^{\circledR}$ (BASF, Malaysia) were procured and used as purchased without further purification.

\section{Methods}

Plant Material. Piper sarmentosum leaves of similar sizes were collected from Taman Pertanian Universiti, Universiti Putra Malaysia and were further identified by a botanist (Dr Mohd Firdaus Ismail) from the Biodiversity Unit, Institute of Bioscience (IBS), Universiti Putra Malaysia. A specimen voucher (MFI 0149/20) was deposited in the Institute of Bioscience Herbarium. The leaves were then washed thoroughly minimise microbial contamination and remove debris and were spread onto trays and oven-dried at $50^{\circ} \mathrm{C}$ for three consecutive days. The leaves were ground into a fine powder using a food blender (Panasonic, Malaysia) and was kept in glass bottles, sealed and wrapped with aluminium foil for protection from sunlight and moisture at room temperature until further use.

Plant Extraction. The leaf extracts of $P$. sarmentosum were obtained by maceration using a shaking incubator (Sartorius, Germany) operating at $150 \mathrm{rpm}$ at room temperature with 
four different solvents, ethyl acetate, methanol, dichloromethane and hexane. Fifteen grams (15 g) of the dried leaf powder were dissolved in $150 \mathrm{~mL}$ of solvents for maceration. The mixture was macerated twice for three consecutive days at room temperature and stored in a dark condition to reduce sample degradation. It was followed by filtration of the crude extract using filter paper (Whatman, England). Finally, filtrates obtained from the maceration were pooled together and further concentrated using a rotary evaporator (Buchi, Switzerland). The dried crude extracts were stored in glass bottles at $4^{\circ} \mathrm{C}$ until further use.

Determination of Total Phenolic Content (TPC). The extract's total phenolic content (TPC) was determined by the Folin-Ciocalteu method as described previously (Ugusman et al., 2012) with modifications. The extracted sample $(0.5 \mathrm{~mL}$ of $1 \mathrm{mg} / \mathrm{mL}$ of different solvent extracts) was mixed with Follin-Ciocalteu reagent $(2.0 \mathrm{~mL}, 1: 10$ diluted with distilled water) for 5 minutes, and an aqueous solution of sodium carbonate $(2.5 \mathrm{~mL}$, $7.5 \% \mathrm{w} / \mathrm{v}$ ) was then added. The mixture was allowed to stand for 90 minutes in a dark condition at room temperature, then estimated phenolic content by colourimetry at $760 \mathrm{~nm}$ (Spectrophotometer, Spectro 23, Labomed, USA). The standard curve ( $\mathrm{y}=0.0046 \mathrm{x}-0.063$, $\left.\mathrm{R}^{2}=0.998\right)$ was prepared by using different concentrations $(0-500 \mu \mathrm{g} / \mathrm{mL})$ of gallic acid solution in aqueous methanol $(10: 90, \mathrm{v} / \mathrm{v})$. The total phenolic content was expressed as a milligram of gallic acid equivalent per gram of the sample dry weight (mg GAE/g DW).

Determination of Total Flavonoid Content (TFC). The extract's total flavonoids content (TFC) was determined by the aluminium chloride colourimetric method as described previously with modifications (Ugusman et al., 2012). Each solvent extract ( $0.5 \mathrm{~mL}, 1 \mathrm{mg}$ / $\mathrm{mL}$ ) was mixed with $2 \mathrm{~mL}$ of distilled water and $0.15 \mathrm{~mL}$ of sodium nitrate $(0.05 \mathrm{M})$. After a 5 minutes incubation at room temperature, $0.15 \mathrm{~mL}$ of aluminium chloride $(0.1 \mathrm{M})$ and $1.0 \mathrm{~mL}$ of sodium hydroxide $(1.0 \mathrm{M})$ were added. The test solution was filled up to $5.0 \mathrm{~mL}$ with distilled water, in which the absorbance was measured at $415 \mathrm{~nm}$ (Spectrophotometer, Spectro 23, Labomed, USA). The standard curve $\left(\mathrm{y}=0.0018 \mathrm{x}-0.0087, \mathrm{R}^{2}=0.9997\right)$ was prepared by using different concentrations $(0-300 \mu \mathrm{g} / \mathrm{mL})$ of quercetin solutions in aqueous methanol $(10: 90, \mathrm{v} / \mathrm{v})$. Total flavonoids content was expressed in milligrams of quercetin per gram of the sample dry weight (mg QE/g DW).

Collection of Mosquito Larvae. The mosquito eggs of susceptible Aedes aegypti ( $A$. aegypti) strain were procured from the Vector Control Research Unit (VCRU), Universiti Sains Malaysia (USM), Penang. Upon arrival, the eggs were immediately transferred into $250 \mathrm{~mL}$ of distilled water containing $0.1 \mathrm{~g}$ of larvae food (fish food-BETTAS ${ }^{\circledR} ; 45 \%$ crude protein, $5 \%$ crude fat, $2 \%$ crude fibre) to trigger the hatching process and provide a continuous supply of nutrients for the larvae growth. The larvae were allowed to grow until the late third instar following hatching prior to treatment. After that, the food was 
replenished every day, and the larvae were maintained at room temperature with 14-h and 10-h dark/light cycles. The larvae were considered ready for treatment on day 7.

Larvicidal Activity. Each of the extracts representing different solvent extraction systems was tested for larvicidal activity at a concentration of $100 \mu \mathrm{g} / \mathrm{mL}$ against the mosquito larvae according to the laboratory guidelines of mosquito larvicide test, provided by the World Health Organization (2005) with several modifications. Four batches of 25 larvae $(\mathrm{N}=100)$ were isolated into a plastic cup for bioassay tests in $50 \mathrm{~mL}$ of the desired extract solution. The dried crude extracts of methanol and ethyl acetate were prepared in methanol, while the dichloromethane and hexane extracts were prepared in DMSO as the stock solutions. The concentration of methanol and DMSO was kept at $0.5 \% \mathrm{v} / \mathrm{v}$ throughout the experiment. Larvae treated with only $0.5 \%$ methanol or DMSO were considered as control. The bioassays were conducted at a temperature in the range of $25-28^{\circ} \mathrm{C}$, with no food supply. Mortality of the larvae was recorded after $24 \mathrm{~h}$ of exposure, and the larvae were considered dead if they did not show any response or movement when the water was disturbed. The mortality percentage was calculated, and the mortality was corrected according to Abbott's formula (Equation 1)(Abbott, 1925). The survived adult mosquitoes were left to die without food supply for three days (De Almeida et al., 2010).

$$
\text { Abbott's corrected mortality }(\%)=\frac{\% \text { test mortality }-\% \text { control mortality }}{100-\% \text { control mortality }} \times 100
$$

Concentration-Response Larvicidal Bioassay. In the concentration-response larvicidal bioassay, all extract solutions were serially diluted to obtain the concentrations in the range of $0-250 \mu \mathrm{g} / \mathrm{mL}$ of test solutions. The concentration of methanol and DMSO was kept at $0.5 \% \mathrm{v} / \mathrm{v}$ throughout the experiment. Each concentration of the test solution was treated on four batches of 25 larvae $(\mathrm{N}=100)$, and the mortality of the larvae was recorded following $24 \mathrm{~h}$ of exposure. The effectiveness of the solvent extracts against the mosquito larvae was compared to a commercial synthetic larvicide, Abate $1.1^{\circledR}$, that contains temephos as the active ingredient at concentrations of $0-10 \mu \mathrm{g} / \mathrm{L}$. Probit analysis was applied to acquire the $\mathrm{LC}_{50}$ and $\mathrm{LC}_{90}$ values (Finney, 1971).

Gas Chromatography-Mass Spectrometry (GC-MS) Analysis. All extracts were subjected to phytochemical analysis using the gas chromatography-mass spectrometry (GC-MS) method. The instrument consisted of a GC-MS QP2010 Plus SHIMADZU (Shimadzu, Japan) system. Compounds were separated on a ZB-5MS column (30 $\mathrm{m} \times$ $0.25 \mathrm{~mm} \mathrm{ID} \times 0.25 \mu \mathrm{m}$ ) and a linear velocity column flow at $1 \mathrm{~mL} / \mathrm{min}$ in a split mode. The column oven was kept at $50^{\circ} \mathrm{C}$ for 3 minutes and was gradually increased to $100^{\circ} \mathrm{C}$ (at $10^{\circ} \mathrm{C} / \mathrm{min}$ ) and to $250^{\circ} \mathrm{C}$ (at $20^{\circ} \mathrm{C} / \mathrm{min}$ ) for 5 minutes. All extracts were dissolved in 
methanol at $5 \mu \mathrm{g} / \mathrm{mL}$, and filtered through the $0.45 \mu \mathrm{m}$ PTFE membrane filter (Millipore, USA) prior to analysis. The GC-MS injection volume was $0.5 \mu \mathrm{L}$ and the analysis was conducted for 7 to 20 minutes. A mass spectrometer equipped with an ACQ detector, set at $240^{\circ} \mathrm{C}$ for ion source temperature and $300^{\circ} \mathrm{C}$ of interface temperature with $\mathrm{m} / \mathrm{z}$ (mass scan) of 35-450 amu, was used to identify the compounds present. The compounds' names, molecular weight and structures were ascertained from the National Institute of Standards and Technology (NIST) 08 mass spectral data library.

Morphological Observation. The morphological abnormalities (head, thorax and abdominal segment) of the treated larvae ( $\mathrm{LC}_{90}$ value) were observed using an inverted microscope (TS100, Nikon, Japan) attached to the DinoLite microscope camera and controlled by the DinoCapture 2.0 software (DinoLite, USA), in comparison to the untreated larvae.

Data Analysis. Results for larvicidal activity, TPC and TFC were expressed as mean \pm standard error of the mean (SEM). Statistical significance was determined by using a one-way analysis of variance (ANOVA) with Tukey's test applied post hoc for paired comparison of means. A $p$-value $\leq 0.05$ was considered as statistically significant (GraphPad Prism 9 Software, United States).

\section{RESULTS AND DISCUSSION}

The methanol extract (ME) obtained the highest percentage yield of $14.73 \%$, followed by ethyl acetate extract (EE), dichloromethane extract (DE), and hexane extract (HE) with percentage yields of $6.38,5.50$ and $2.23 \%$, respectively. The percentage yield of HE was higher than a previous study (Hematpoor et al., 2016) that reported a percentage yield of only $0.97 \%$ for HE extracted from the roots of $P$. sarmentosum. The difference in the percentage yield obtained was due to the different parts of the plant used and the polarity of each solvent.

The Folin-Ciocalteu method used to determine the total phenolic content (TPC) depends largely on the electrons transfer from the hydroxyl group directly bonded to the aromatic hydrocarbon group in the phenolic compounds. It leads to forming of a blue chromophore constituted by a mixture of a heteropolyphosphotungstates-molybdates complex in an alkaline condition (Blainski et al., 2013), which results in a maximum absorption at a wavelength of $760 \mathrm{~nm}$. The TPC values of ME, EE, DE and HE were calculated according to a constructed regression equation $\left(y=0.0046 \mathrm{x}-0.063, \mathrm{R}^{2}=0.9980\right)$, and the values were interpreted as mean $\pm \mathrm{SEM}$ (mg GAE/g DW). HE exhibited the highest TPC value $(26.68 \pm 0.22)$ followed by DE $(19.93 \pm 0.13)$, EE $(19.75 \pm 0.10)$, and ME $(17.25 \pm 0.12)$ (Table 1). There is a significant difference in multiple comparisons between the extracts, except for $\mathrm{EE}$ and $\mathrm{DE}$. 
TFC was calculated from the regression equation $\left(y=0.0018 x-0.0087, R^{2}=0.9997\right)$ and was interpreted as mean $\pm \mathrm{SEM}$ (mg QE/g DW). The results obtained displayed that $\mathrm{HE}$ has the highest total flavonoids content of $18.99 \pm 0.07$, followed by DE $(13.33 \pm 0.12)$, $\mathrm{EE}(10.04 \pm 0.06)$, and ME $(4.38 \pm 0.05)$ (Table 1). The results indicate that flavonoids with higher molecular weight were able to be extracted in organic solvents (Zaidan et al., 2019), which is congruent with the previous studies by Lee et al. (2014) and Tuekaew et al. (2014). The flavonoid compounds in the extracts may be influenced by the part of the plant used, cultivation location, and most importantly, the solvent extraction system applied, which are the essential factors to be considered when comparing to previous studies (Zaidan et al., 2018, Altemimi et al., 2017, Anokwuru et al., 2011).

Table 1

Total phenolic and flavonoid contents of different solvent extracts of P. sarmentosum leaves

\begin{tabular}{|c|c|c|}
\hline \multirow{2}{*}{ Solvent Extracts } & \multicolumn{2}{|c|}{ Mean $\pm \operatorname{SEM}(n=3)$} \\
\hline & TPC (mg GAE/g DW) ${ }^{1}$ & TFC (mg QE/g DW) $)^{2}$ \\
\hline Methanol Extract (ME) ${ }^{*}$ & $17.25 \pm 0.12$ & $4.38 \pm 0.05$ \\
\hline Ethyl acetate Extract $(\mathrm{EE})^{*}$ & $19.75 \pm 0.10$ & $10.04 \pm 0.06$ \\
\hline Dichloromethane Extract (DE) ${ }^{*}$ & $19.93 \pm 0.13$ & $13.33 \pm 0.12$ \\
\hline Hexane Extract (HE) & $26.68 \pm 0.22$ & 1.99 \\
\hline
\end{tabular}

*Denotes significant difference to HE $(p \leq 0.05)$. No significant difference was observed for EE and DE $(p$ $>0.05)$

The highest larvicidal activity of $P$. sarmentosum leaves extract was displayed by HE with a percentage mortality of $100 \%$, followed by DE $(67.00 \pm 0.66 \%)$, EE $(24.00 \pm 0.80 \%)$, and $\mathrm{ME}(18.00 \pm 0.40 \%)$ at $100 \mu \mathrm{g} / \mathrm{mL}$ as shown in Table 2 . The untreated larvae exposed to only $0.5 \%$ DMSO and methanol showed no significant mortality effect (Table 2 ). The highest larvicidal activity exhibited by HE was attributed to the presence of high phenolic and flavonoid compounds in the extract (Table 1). It was supported by a study conducted by Vimaladevi et al. (2012), which revealed that insoluble bound, soluble conjugated and free phenolic acid fractions of Chaetomorpha antennina had excellent larvicidal activity against $A$. aegypti with $\mathrm{LC}_{50}$ values of $23.4,44.6$ and $60.8 \mu \mathrm{g} / \mathrm{L}$, respectively. In another study, there was a linear correlation between the total phenolic content of the selected Egyptian plants (aqueous and methanol extracts) and the larvicidal activity against $A$. aegypti (El-Hela et al., 2013).

The larvae of the $A$. aegypti were then exposed to different solvent extracts of $P$. sarmentosum at various concentrations of the test solutions $(0-250 \mu \mathrm{g} / \mathrm{mL})$. The mortality percentage was shown to be concentration-dependent (Figure 1). A significantly higher larvicidal activity of $P$. sarmentosum leaves extract was displayed by $\mathrm{HE}$ with $\mathrm{LC}_{50}$ and $\mathrm{LC}_{90}$ values of 39.04 and $87.84 \mu \mathrm{g} / \mathrm{mL}$, followed by DE $(62.78$ and $134.73 \mu \mathrm{g} / \mathrm{mL}), \mathrm{EE}$ (114.70 and $169.20 \mu \mathrm{g} / \mathrm{mL})$, and ME (156.10 and $182.10 \mu \mathrm{g} / \mathrm{mL})$, respectively as shown 
in Figure 2. Abate $1.1^{\circledR}$ displayed superior efficacy of larvicidal activity with $\mathrm{LC}_{50}$ and $\mathrm{LC}_{90}$ values of 5.49 and $7.67 \mu \mathrm{g} / \mathrm{L}$, respectively (Table 3). Abate $1.1^{\circledR}$ has been used extensively and intensively in controlling the Aedes mosquito larvae in Malaysia, which has contributed largely to the emergence of temephos resistance (Mohiddin et al., 2016). Moreover, the $\mathrm{LC}_{50}$ value of $P$. sarmentosum leaves HE $(39.04 \mu \mathrm{g} / \mathrm{mL})$ was lower compared to the results from previous studies within the same species, $49.19 \mu \mathrm{g} / \mathrm{mL}$ (Intirach et al., 2016), which utilised essential oil extracted from $P$. sarmentosum against the larvae of $A$. aegypti. In another study by Hematpoor et al. (2016), the crude HE extracted from the roots of $P$. sarmentosum only exhibits $100 \%$ mortality towards Aedes aegypti at $250 \mu \mathrm{g} / \mathrm{mL}$. Thus, it indicates a significantly improved larvicidal activity of $P$. sarmentosum from the leaves extract. Contrary to the $\mathrm{HE}$ used in the present study, the lower $\mathrm{LC}_{50}$ value of 4.06 $\mu \mathrm{g} / \mathrm{mL}$ reported by Chaithong et al. (2006) could be possibly contributed by more active compounds in the extract obtained from the whole plant of $P$. sarmentosum.

Table 2

Larvicidal activity of $P$. sarmentosum leaves extracts against A. aegypti at $100 \mu \mathrm{g} / \mathrm{mL}$

\begin{tabular}{lc}
\hline Solvent Extracts & Mean mortality $\pm \operatorname{SEM}(\%)(N=100)$ \\
\hline Methanol Extract (ME) ${ }^{*}$ & $18.00 \pm 0.40$ \\
Ethyl acetate Extract $(\mathrm{EE})^{*}$ & $24.00 \pm 0.80$ \\
Dichloromethane Extract $(\mathrm{DE})^{*}$ & $67.00 \pm 0.66$ \\
Hexane Extract (HE) & $100.00 \pm 0.00$ \\
Control (0.5\% Methanol) & $2.00 \pm 0.06$ \\
Control (0.5\% DMSO) & $0.00 \pm 0.00$ \\
\hline
\end{tabular}

*Denotes significant difference to $\operatorname{HE}(p \leq 0.05)$.

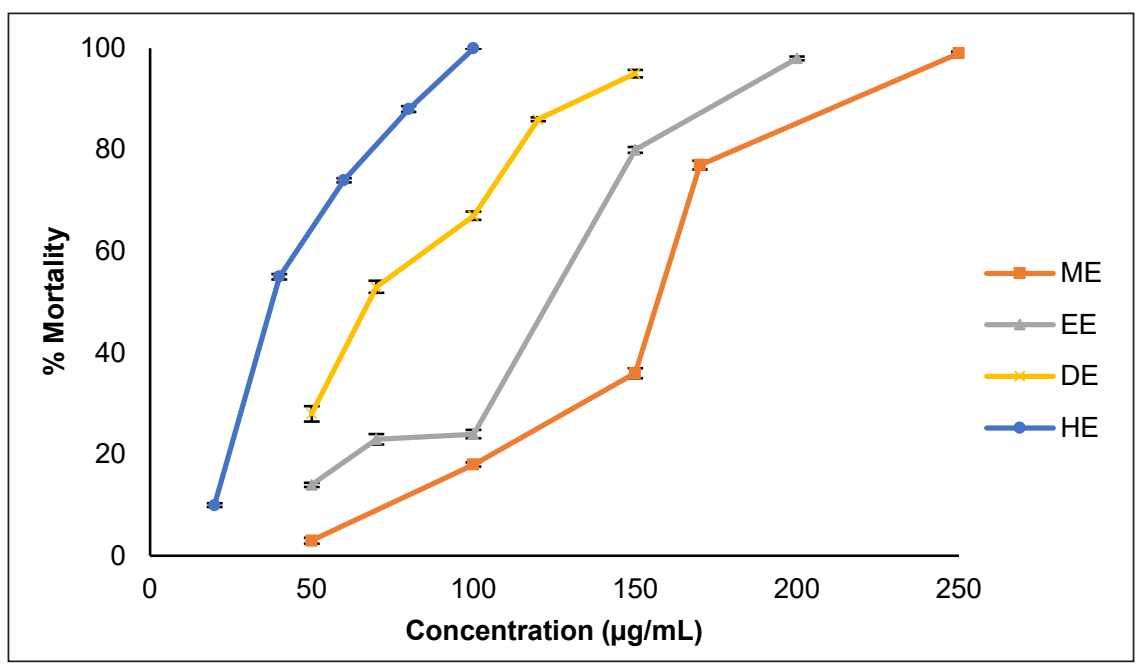

Figure 1. Concentration-response of the percentage of mortality of $P$. sarmentosum leaves extracts in hexane (HE), dichloromethane (DE), ethyl acetate (EE) and methanol (ME) against A. aegypti larvae at various concentrations of $0-250 \mu \mathrm{g} / \mathrm{mL}$ post-exposure $(24 \mathrm{~h})$. Data represent the value of mean $\pm \mathrm{SEM}(\mathrm{N}=100)$. 


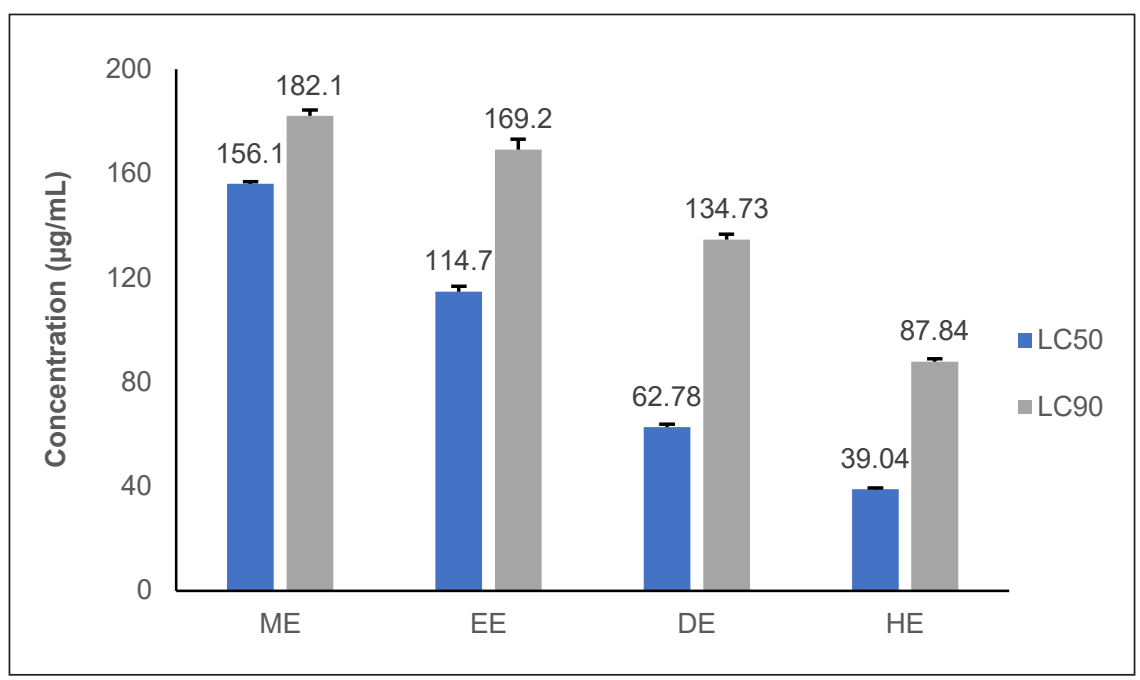

Figure 2. The larvicidal activity presented as $\mathrm{LC}_{50}$ and $\mathrm{LC}_{90}$ values of different solvent extracts of $\mathrm{P}$. sarmentosum leaves; methanol extract (ME), ethyl acetate extract (EE), dichloromethane extract (DE) and hexane extract (HE) against $A$. aegypti larvae. Data presented as mean \pm SEM $(\mathrm{N}=100)$. * Indicates significant difference to $\mathrm{HE}$ at $\mathrm{p} \leq 0.05$ of $95 \%$ confident interval (Tukey's Test).

Phytochemical profiling of $P$. sarmentosum leaves extracts was obtained by using the high-performance GC-MS method. The most prevailing phytochemicals in all extracts were found to be phenylpropanoids ( $Z$-isoelemicin and asarone). ME contained $(Z)$ - isoelemicin $(26.12 \%)$ and asarone $(26.32 \%)$, EE; $(Z)$ - isoelemicin $(27.10 \%)$ and asarone $(29.91 \%)$, DE; (Z)- isoelemicin (38.68\%) and asarone (34.08\%) and HE; (Z)- isoelemicin (44.82\%) and asarone (35.23\%), respectively (Table 4). The higher efficacy of DE and HE compared to $\mathrm{ME}$ and $\mathrm{EE}$ are contributed to the additional compound of myristicin with a yield of $6.33 \%$ in DE and $9.03 \%$ in HE. Furthermore, the high yield of these phenylpropanoids was correlated with the larvicidal activity of $P$. sarmentosum leaves extracts against $A$. aegypti.

The current study's component proportions (isoelemicin, asarone, myristicin) of $P$. sarmentosum leaves extracts correspond to several previous studies within the same species (Abidin et al., 2020, Chanprapai \& Chavasiri, 2017, Rahman et al., 2014, Qin et al. 2010). Isoelemicin was also found as the major composition in ethyl acetate extract of $P$. solmsianum leaves (Martins et al., 2000), (Z)-isoelemicin (21.5\%) in P. mikanianum essential oil (Leal et al., 2005) and E-isoelemicin (40.81\%) in P. rivinoides leaves essential oil (Leal et al., 2019). (Z)-Asarone (30.4\%) appeared as the major constituent in the essential oil of $P$. marginatum leaves (Ribeiro et al., 2016). The presence of asarone and myristicin could be the main contributor to the potent larvicidal activity of HE compared to other extracts. Several studies have reported that different asarone stereoisomers exhibited different potential in larvicidal activity against $A$. aegypti larvae. $\beta$-asarone extracted from the root 
Table 3

Comparative larvicidal activity of different solvent extracts of $\mathrm{P}$. sarmentosum leaves and temephos (Abate 1.1) against $\mathrm{A}$. aegypti larvae

\begin{tabular}{|c|c|c|c|}
\hline \multirow{2}{*}{ Extract $(\mu \mathrm{g} / \mathrm{mL})$} & \multirow{2}{*}{ *Mean mortality \pm SEM (\%) } & \multicolumn{2}{|c|}{$\mathrm{LC}$ values $(95 \% \mathrm{CI}, \mu \mathrm{g} / \mathrm{mL})$} \\
\hline & & $\mathrm{LC}_{50}$ & $\mathrm{LC}_{90}$ \\
\hline \multicolumn{4}{|l|}{ Methanol Extract (ME) } \\
\hline 50 & $3.00 \pm 0.59$ & \multirow{5}{*}{$\begin{array}{c}156.10 \\
(155.30-156.90)\end{array}$} & \multirow{5}{*}{$\begin{array}{c}182.10 \\
(179.8-184.40)\end{array}$} \\
\hline 100 & $18.00 \pm 0.40$ & & \\
\hline 150 & $36.00 \pm 0.97$ & & \\
\hline 170 & $77.00 \pm 0.87$ & & \\
\hline 250 & $99.00 \pm 0.35$ & & \\
\hline \multicolumn{4}{|l|}{ Ethyl acetate Extract (EE) } \\
\hline 50 & $14.00 \pm 0.40$ & \multirow{5}{*}{$\begin{array}{c}114.70 \\
(112.60-116.80)\end{array}$} & \multirow{5}{*}{$\begin{array}{c}169.20 \\
(165.20-173.20)\end{array}$} \\
\hline 70 & $23.00 \pm 1.04$ & & \\
\hline 100 & $24.00 \pm 0.80$ & & \\
\hline 150 & $80.00 \pm 0.57$ & & \\
\hline 200 & $98.00 \pm 0.40$ & & \\
\hline \multicolumn{4}{|c|}{ Dichloromethane Extract (DE) } \\
\hline 50 & $28.00 \pm 1.50$ & \multirow{5}{*}{$\begin{array}{c}66.32 \\
(65.26-67.38)\end{array}$} & \multirow{5}{*}{$\begin{array}{c}131.83 \\
(129.81-133.85)\end{array}$} \\
\hline 70 & $53.00 \pm 1.18$ & & \\
\hline 100 & $67.00 \pm 0.66$ & & \\
\hline 120 & $86.00 \pm 0.40$ & & \\
\hline 150 & $95.00 \pm 0.74$ & & \\
\hline \multicolumn{4}{|l|}{ Hexane Extract (HE) } \\
\hline 20 & $10.00 \pm 0.40$ & \multirow{7}{*}{$\begin{array}{c}39.04 \\
(38.59-39.49)\end{array}$} & \multirow{7}{*}{$\begin{array}{c}87.84 \\
(86.65-89.04)\end{array}$} \\
\hline 40 & $55.00 \pm 0.52$ & & \\
\hline 60 & $74.00 \pm 0.40$ & & \\
\hline 80 & $88.00 \pm 0.57$ & & \\
\hline 100 & $100.00 \pm 0.00$ & & \\
\hline Control $(0.5 \% \mathrm{MeOH})$ & $2.00 \pm 0.40$ & & \\
\hline Control (0.5\% DMSO) & - & & \\
\hline \multirow{2}{*}{ Larvicide $(\mu \mathrm{g} / \mathrm{L})$} & \multirow{2}{*}{$*$ Mean mortality \pm SEM $(\%)$} & \multicolumn{2}{|c|}{ LC values $(\mu \mathrm{g} / \mathrm{L})$} \\
\hline & & $\mathrm{LC}_{50}$ & $\mathrm{LC}_{90}$ \\
\hline \multicolumn{4}{|l|}{ Temephos (Abate $\left.1.1^{\circledR}\right)$} \\
\hline 2 & $6.00 \pm 0.40$ & \multirow{5}{*}{$\begin{array}{c}5.49 \\
(5.42-5.56)\end{array}$} & \multirow{5}{*}{$\begin{array}{c}7.67 \\
(7.62-7.75)\end{array}$} \\
\hline 4 & $23.00 \pm 0.11$ & & \\
\hline 6 & $52.00 \pm 0.86$ & & \\
\hline 8 & $97.00 \pm 0.38$ & & \\
\hline 10 & $100.00 \pm 0.00$ & & \\
\hline Control (distilled water) & - & & \\
\hline
\end{tabular}

Note. *Mean value of four replicates, $\mathrm{N}=100$ 
bark of Cordia alliodora has shown a minimal concentration of $25 \mu \mathrm{g} / \mathrm{mL}$ to kill all tested larvae (Ioset et al., 2000) and at $\mathrm{LC}_{50}$ value of $26.99 \mu \mathrm{g} / \mathrm{mL}$ from Asarum heterotropoides roots (Perumalsamy et al., 2009). However, asarone isomers have demonstrated mammalian carcinogenic effects (Haupenthal et al., 2017, Uebel et al., 2020). On the other hand, myristicin was found to be one of the major components in P. permucronatum $(25.61 \%)$ and P. hostmanianum (20.26\%) (de Morais et al., 2007). Myristicin previously has been reported to possess insecticidal effect against Spilarctia obliqua (Srivastava et al., 2001). A study by Seo et al. (2015) has revealed a significant efficacy of myristicin from the essential oil of Illicium difengpi against $A$. aegypti larvae with an $\mathrm{LC}_{50}$ value of $15.26 \mu \mathrm{g} / \mathrm{mL}$. At $50 \mu \mathrm{g} / \mathrm{mL}$ of myristicin treatment, $92.5 \%$ mortality resulted against Ae. albopictus larvae (Seo et al., 2015). According to Hematpoor et al. (2016), three active phenylpropanoids: asaricin, isoasarone and trans-asarone were identified and isolated by hexane extraction from the roots of $P$. sarmentosum. Asaricin and isoasarone were highly potent against Aedes aegypti, Aedes albopictus and Culex quinquefasciatus larvae causing up to $100 \%$ mortality at $\leq 15 \mu \mathrm{g} / \mathrm{mL}$ of concentration. These findings coupled with the high acetylcholinesterase (AChE) inhibition suggest that asaricin and isoasarone are neurotoxic compounds towards Aedes aegypti, Aedes albopictus, and Culex quinquefasciatus. The variations in the type of phytochemicals present in $P$. sarmentosum extracts were contributed by plant species, plant parts used, age of plant parts, geographical origin of the plant and solvent used for extraction (Ghosh et al., 2012). Solvents with different polarities could cause different compounds to be extracted (Ugusman et al., 2012, Shaalan et al., 2005).

After several hours of treatment, the larvae lost their mobility when exposed to the test solutions. After $24 \mathrm{~h}$ of exposure to $\mathrm{HE}$ ( $\mathrm{LC}_{90}$ value), the dead larvae were observed for morphological changes under an inverted microscope. The observation displayed alterations in the internal structure of the abdominal segment and the siphon (Figures $3 a \&$ $3 \mathrm{~b}$ ), compared to the untreated larvae with no abnormal alteration and normal appearance of the siphon structure (Figures 3c \& 3d).

The present study's findings agree with the previous study of Chaithong et al. (2006), in which the pepper-treated larvae displayed remarkable shrinkage of anal papillae. However, HE clearly showed delayed toxicity when a few moribund larvae (do not respond when disturbed) still displayed pounding heartbeats upon $24 \mathrm{~h}$ of exposure. Thus, it indicates a slower action of HE in larvae killing and was probably only targeting the neuromuscular system (Sakthivadivel \& Thilagavathy, 2003), as the moribund larvae showed partial paralysis after treatment. In addition, the structural alterations of the internal tracheal tube and abdomen segment may demonstrate respiratory and gastrointestinal tract failure, leading to the larvae's dysfunction and death. 
Table 4

Chemical composition of methanol extract (ME), ethyl acetate extract (EE), dichloromethane extract and hexane extract (HE) of $\mathrm{P}$. sarmentosum leaves

\begin{tabular}{|c|c|c|c|c|c|c|}
\hline \multirow{2}{*}{ Compounds } & \multirow{2}{*}{ MW } & \multirow{2}{*}{ RI } & \multicolumn{4}{|c|}{ Peak area $(\%)$} \\
\hline & & & $\mathrm{ME}$ & $\mathrm{EE}$ & $\mathrm{DE}$ & $\mathrm{HE}$ \\
\hline 4,8-dimethylnonanol & 172 & 1229 & - & - & 0.25 & - \\
\hline 2-Butyloctanol & 186 & 1393 & 1.12 & - & - & - \\
\hline 1-Tetradecene & 196 & 1403 & 2.47 & - & - & - \\
\hline 1,6-heptadiene-2-methyl-6-phenyl- & 186 & 1424 & 2.64 & 1.76 & - & - \\
\hline Decane-1-iodo & 268 & 1430 & 1.60 & - & - & - \\
\hline Cyclopentanecarboxylic acid & 208 & 1456 & 1.51 & - & - & - \\
\hline Caryophyllene & 204 & 1494 & 1.20 & 1.55 & 3.28 & 0.59 \\
\hline Bicyclogermacrene & 204 & 1497 & - & 0.08 & - & - \\
\hline 1,3-Benzodioxole-4-methoxy-6-(2-propenyl) & 192 & 1516 & 2.80 & - & - & - \\
\hline$\delta$-Cadinene & 204 & 1518 & - & 0.61 & 0.32 & - \\
\hline Myristicin & 192 & 1520 & - & 3.23 & 6.33 & 9.03 \\
\hline Cyclohexanemethanol & 222 & 1522 & - & 0.25 & 0.33 & - \\
\hline Elemicin & 208 & 1551 & 0.39 & 0.32 & 0.30 & 0.59 \\
\hline Phenol-2,4-bis(1,1-dimethylethyl) & 206 & 1555 & 3.29 & 2.21 & 0.30 & - \\
\hline 1-Dodecanol-3,7,11-trimethyl & 228 & 1563 & - & 0.42 & - & - \\
\hline (Z)-Isoelemicin & 208 & 1565 & 26.12 & 27.10 & 38.68 & 44.82 \\
\hline Asarone & 208 & 1568 & 26.32 & 29.91 & 34.08 & 35.23 \\
\hline (Z)- $\beta$-Asarone & 208 & 1568 & 0.49 & 0.47 & - & - \\
\hline 1-naphthalenol & 222 & 1580 & 0.72 & - & - & - \\
\hline Dillapiole & 210 & 1621 & - & 1.43 & - & - \\
\hline$\alpha$-Muurolol & 222 & 1651 & - & 0.62 & 0.63 & 0.96 \\
\hline Apiole & 222 & 1683 & - & 0.94 & 1.61 & 2.10 \\
\hline Apiol & 222 & 1705 & 0.84 & - & 1.12 & 2.09 \\
\hline 2-Propenoic acid, 3-(3,4-dimethoxyphenyl & 208 & 1735 & - & - & - & 0.89 \\
\hline Hexahydrofarnesyl acetone & 268 & 1754 & 0.66 & - & - & 0.69 \\
\hline Neophytadiene & 278 & 1836 & 4.69 & 8.55 & 6.78 & 2.17 \\
\hline 1,5-diphenyl-2-pentene & 222 & 1872 & 1.35 & - & - & - \\
\hline Palmitic acid & 270 & 1878 & 4.21 & 5.14 & - & - \\
\hline 3-methyl-2-(3,7,11-trimethyldodecyl) furan & 292 & 1931 & 0.37 & - & - & - \\
\hline Methyl isostearate & 298 & 2013 & - & 3.52 & - & - \\
\hline Phytol & 296 & 2045 & 4.70 & 7.87 & 5.99 & 0.84 \\
\hline 3-Methyl-2-(3,7,11-trimethyldodecy) & 392 & 2045 & - & 0.45 & - & - \\
\hline Octadecanoic acid, methyl ester & 298 & 2077 & 4.53 & - & - & - \\
\hline (Z)-6-Octadecenoic acid, methyl ester & 296 & 2085 & 3.10 & 2.80 & & \\
\hline $\begin{array}{l}\text { Benzenepropanoic acid, 3,5-bis(1,1- } \\
\text { dimethylethyl)-4-hydroxy }\end{array}$ & 292 & 2134 & 4.88 & - & - & - \\
\hline Piperidine & 281 & 2366 & - & 0.77 & - & - \\
\hline Total identified (\%) & & & 100 & 100 & 100 & 100 \\
\hline
\end{tabular}

Note. MW: Molecular Weight; RI: Retention Index 


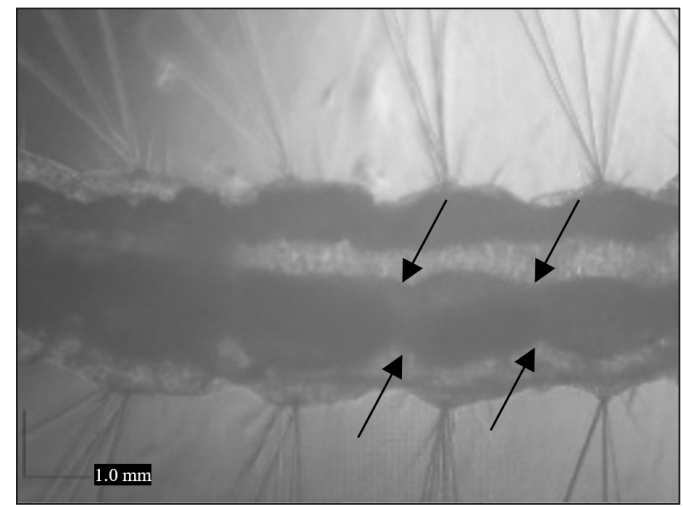

(a)

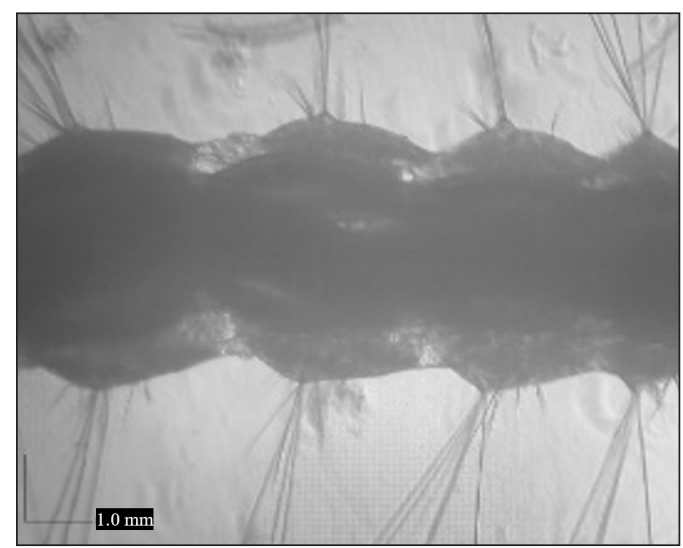

(c)

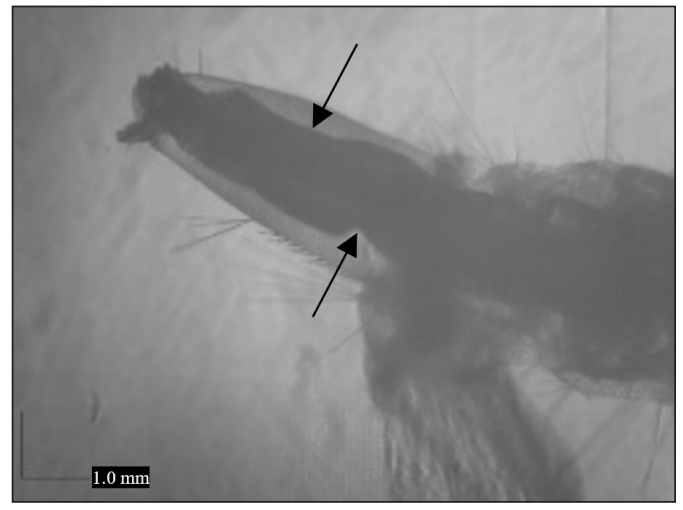

(b)

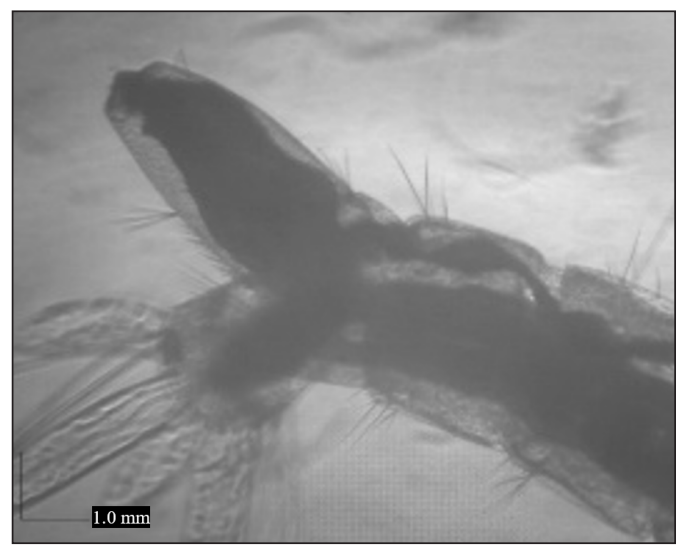

(d)

Figure 3. Morphological alterations in the treated larvae ( $\mathrm{LC}_{90}$ of $\mathrm{HE}$ ) with significant shrinkage of the internal structure of (a) abdominal segment and the (b) siphon as indicated by arrows. No alterations were observed on untreated larvae of the (c) internal structure of the abdominal segment and (d) the internal structure of the siphon. Scale bar represents $1.0 \mathrm{~mm}$ at $40 \times$ magnification.

\section{CONCLUSION}

Botanical resources can be an alternative to the problematic synthetic larvicides in controlling the mosquito vector population. In this study, HE of P. sarmentosum leaves exhibited the highest potential of larvicidal activity with an $\mathrm{LC}_{50}$ value of $39.04 \mu \mathrm{g} / \mathrm{mL}$ and $\mathrm{LC}_{90}$ value of $87.84 \mu \mathrm{g} / \mathrm{mL}$, compared to other solvent extracts. Morphological alterations of the internal abdominal segment and siphon of the treated larvae indicate acute toxicity of HE. It is suggested that the presence of various bioactive compounds at a higher percentage in $\mathrm{HE}$ exert synergistic effects on the significantly improved larvicidal activity of HE compared to other solvent extracts. However, further research that focuses on the larvicidal mechanism of the HE, susceptibility, stability and toxicity of the HE towards non-targeted organisms is warranted for the HE to be developed as a potential alternative for synthetic larvicides. 


\section{ACKNOWLEDGMENTS}

The research was financially supported by a research grant provided by the Ministry of Higher Education of Malaysia, namely the Fundamental Research Grant Scheme (FRGSFRGS/1/2018/SKK11/UPM/02/1). In addition, the authors acknowledge the facilities and technical assistance provided by the Institute of Biosciences (IBS) at Universiti Putra Malaysia.

\section{REFERENCES}

Abbott, W. S. (1925). A method of computing the effectiveness of an insecticide. Journal of Economic Entomology, 18(2), 265-267.

Abidin, I. Z. Z., Fazry, S., Jamar, N. H., Dyari, H. R. E., Ariffin, Z. Z., Johari, A. N., Ashaari, N. S., Johari, N. A., Wahab, R. M. A., \& Ariffin, S. H. Z. (2020). The effects of Piper sarmentosum aqueous extracts on zebrafish (Danio rerio) embryos and caudal fin tissue regeneration. Scientific Reports, 10(1), Article 14165. https://doi.org/10.1038/s41598-020-70962-7

Altemimi, A., Lakhssassi, N., Baharlouei, A., Watson, D., \& Lightfoot, D. (2017). Phytochemicals: Extraction, isolation, and identification of bioactive compounds from plant extracts. Plants, 6(4), Article 42. https:// doi.org/10.3390/plants6040042

Anadu, D. I., Aanaso, H. U., \& Onyeka, O. N. D. (1996). Acute toxicity of the insect larvicide abate ${ }^{\circledR}$ (temephos) on the fish Tilapia melanopleura and the dragonfly larvae Neurocordelia virginiensis. Journal of Environmemtal Science and Health, 31(6), 1363-1375. https://doi.org/10.1080/03601239609373072

Anokwuru, C. P., Anyasor, G. N., Ajibaye, O., Fakoya, O., \& Okebugwu, P. (2011). Effect of extraction solvents on phenolic, flavonoid and antioxidant activities of three Nigerian medicinal plants. Nature and Science, 9(7), 53-61.

Blainski, A., Lopes, G., \& de Mello, J. (2013). Application and analysis of the folin ciocalteu method for the determination of the total phenolic content from Limonium Brasiliense L. Molecules, 18(6), 6852-6865. https://doi.org/10.3390/molecules 18066852

Chaithong, U., Choochote, W., Kamsuk, K., Jitpakdi, A., Chaiyasit, D., Champakaew, D., Tuetun, B., Pitasawat, B., \& Tippawangkosol, P. (2006). Larvicidal effect of pepper plants on Aedes aegypti (L.) (Diptera: Culicidae). Journal of Vector Ecology, 31(1), 138-144. https://doi.org/10.3376/10811710(2006)31[138:LEOPPO]2.0.CO;2

Chanprapai, P., \& Chavasiri, W. (2017). Antimicrobial activity from Piper sarmentosum Roxb. against rice pathogenic bacteria and fungi. Journal of Integrative Agriculture, 16(11), 2513-2524. https://doi. org/10.1016/S2095-3119(17)61693-9

De Almeida, S. J., Ferreira, R. P. M., Eiras, Á. E., Obermayr, R. P., \& Geier, M. (2010). Multi-agent modeling and simulation of an Aedes aegypti mosquito population. Environmental Modelling \& Software, 25(12), 1490-1507. https://doi.org/10.1016/j.envsoft.2010.04.021

de Morais, S. M., Facundo, V. A., Bertini, L. M., Cavalcanti, E. S. B., dos Anjos Júnior, J. F., Ferreira, S. A., de Brito, E. S., \& de Souza Neto, M. A. (2007). Chemical composition and larvicidal activity of essential 
oils from Piper species. Biochemical Systematics and Ecology, 35(10), 670-675. https://doi.org/10.1016/j. bse.2007.05.002

El-Hela, A. A., Abdel-Hady, N. M., \& Dawoud, G. T. M. (2013). Phenolic content, antioxidant potential and Aedes aegyptii ecological friend larvicidal activity of some selected Egyptian plants. Journal of the Egyptian Society of Parasitology, 43(1), 215-234. https://doi.org/10.12816/0006379

Finney, D. J. (1971). Probit analysis (3rd ed.). Cambridge University Press.

Ghosh, A., Chowdhury, N., \& Chandra, G. (2012). Plant extracts as potential mosquito larvicides. Indian Journal of Medical Research, 135(5), 581-598. /pmc/articles/PMC3401688/

Guleria, S., \& Tiku, A. K. (2009). Botanicals in pest management: Current status and future perspectives. In Integrated Pest Management: Innovation-Development Process (pp. 317-329). Springer. https://doi. org/10.1007/978-1-4020-8992-3_12

Haupenthal, S., Berg, K., Gründken, M., Vallicotti, S., Hemgesberg, M., Sak, K., Schrenk, D., \& Esselen, M. (2017). In vitro genotoxicity of carcinogenic asarone isomers. Food and Function, 8(3), 1227-1234. https://doi.org/10.1039/c6fo01701k

Hematpoor, A., Liew, S. Y., Chong, W. L., Azirun, M. S., Lee, V. S., \& Awang, K. (2016). Inhibition and larvicidal activity of phenylpropanoids from Piper sarmentosum on acetylcholinesterase against mosquito vectors and their binding mode of interaction. PLOS ONE, 11(5), 1-27. https://doi.org/10.1371/journal. pone. 0155265

Intirach, J., Junkum, A., Lumjuan, N., Chaithong, U., Jitpakdi, A., Riyong, D., Wannasan, A., Champakaew, D., Muangmoon, R., Chansang, A., \& Pitasawat, B. (2016). Antimosquito property of Petroselinum crispum (Umbellifereae) against the pyrethroid resistant and susceptible strains of Aedes aegypti (Diptera: Culicidae). Environmental Science and Pollution Research, 23(23), 23994-24008. https://doi.org/10.1007/ s11356-016-7651-8

Ioset, J. R., Marston, A., Gupta, M. P., \& Hostettmann, K. (2000). Antifungal and larvicidal compounds from the root bark of Cordia alliodora. Journal of Natural Products, 63(3), 424-426. https://doi.org/10.1021/ np990393j

Leal, A. L. A. B., Machado, A. J. T., Bezerra, C. F., Inácio, C. E. S., Rocha, J. E., Sales, D. L., de Freitas, T. S., de Oliveira Almeida, W., do Amaral, W., da Silva, L. E., Ferriani, A. P., de Noronha Sales Maia, B. H. L., Morais-Braga, M. F. B., Barreto, H. M., \& Coutinho, H. D. M. (2019). Chemical identification and antimicrobial potential of essential oil of Piper rivinoides kunth (BETIS-WHITE). Food and Chemical Toxicology, 131, Article 110559. https://doi.org/10.1016/j.fct.2019.06.006

Leal, L. F., Miguel, O. G., Silva, R. Z., Yunes, R. A., Santos, A. S., \& Miguel, O. G. (2005). Chemical composition of Piper mikanianum essential oil. Journal of Essential Oil Research, 17(3), 316-317. https:// doi.org/10.1080/10412905.2005.9698916

Lee, J. H., Cho, S., Paik, H. D., Choi, C. W., Nam, K. T., Hwang, S. G., \& Kim, S. K. (2014). Investigation on antibacterial and antioxidant activities, phenolic and flavonoid contents of some Thai edible plants as an alternative for antibiotics. Asian-Australasian Journal of Animal Sciences, 27(10), 1461-1468. https:// doi.org/10.5713/ajas.2013.13629 
Mahmood, Q., Bilal, M., \& Jan, S. (2014). Herbicides, pesticides, and plant tolerance: An overview. Emerging Technologies and Management of Crop Stress Tolerance, 1, 423-448. https://doi.org/10.1016/B978-012-800876-8.00017-5

Martins, R. C. C., Latorre, L. R., Sartorelli, P., \& Kato, M. J. (2000). Phenylpropanoids and tetrahydrofuran lignans from Piper solmsianum. Phytochemistry, 55(7), 843-846. https://doi.org/10.1016/S00319422(00)00295-8

Ministry of Health Malaysia. (2020). Kenyataan Akhbar Ketua Pengarah Kesihatan Malaysia Situasi Semasa Deman Denggi, Zika dan Chikungunya Di Malaysia-ME 482020 [Press statement of the director general of health Malaysia: Current situation of Dengue Fever, Zika and Chikungunya in Malaysia- ME 48 2020]. Portal Rasmi Kementerian Kesihatan Malaysia.

Mohiddin, A., Lasim, A. M., \& Zuharah, W. F. (2016). Susceptibility of Aedes albopictus from dengue outbreak areas to temephos and Bacillus thuringiensis subsp. israelensis. Asian Pacific Journal of Tropical Biomedicine, 6(4), 295-300. https://doi.org/10.1016/j.apjtb.2016.01.006

Perumalsamy, H., Kim, N. J., \& Ahn, Y. J. (2009). Larvicidal activity of compounds isolated from Asarum heterotropoides against Culex pipiens pallens, Aedes aegypti, and Ochlerotatus togoi (Diptera: Culicidae). Journal of Medical Entomology, 46(6), 1420-1423. https://doi.org/10.1603/033.046.0624

Qin, W., Huang, S., Li, C., Chen, S., \& Peng, Z. (2010). Biological activity of the essential oil from the leaves of Piper sarmentosum Roxb. (Piperaceae) and its chemical constituents on Brontispa longissima (Gestro) (Coleoptera: Hispidae). Pesticide Biochemistry and Physiology, 96(3), 132-139. https://doi.org/10.1016/J. PESTBP.2009.10.006

Rahman, S. F. S. A., Sijam, K., \& Omar, D. (2014). Chemical composition of Piper sarmentosum extracts and antibacterial activity against the plant pathogenic bacteria Pseudomonas fuscovaginae and Xanthomonas oryzae pv. oryzae. Journal of Plant Diseases and Protection, 121(6), 237-242. https://doi.org/10.1007/ BF03356518

Reiter, P. (2001). Climate change and mosquito-borne disease. Environmental Health Perspectives, 109(1), 141-161. https://doi.org/10.1289/ehp.01109s1141

Ribeiro, N., Camara, C., \& Ramos, C. (2016). Toxicity of essential oils of Piper marginatum Jacq. against Tetranychus urticae Koch and Neoseiulus Californicus (McGregor). Chilean Journal of Agricultural Research, 76(1), 71-76. https://doi.org/10.4067/S0718-58392016000100010

Sakthivadivel, M., \& Thilagavathy, D. (2003). Larvicidal and chemosterilant activity of the acetone fraction of petroleum ether extract from Argemone mexicana L. seed. Bioresource Technology, 89(2), 213-216. https://doi.org/10.1016/S0960-8524(03)00038-5

Salleh, W. M. N. H. W., Hashim, N. A., Ahmad, F., \& Heng Yen, K. (2014). Anticholinesterase and antityrosinase activities of ten piper species from malaysia. Advanced Pharmaceutical Bulletin, 4(Suppl 2), 527-531. https://doi.org/10.5681/apb.2014.078

Seo, S. M., Jung, C. S., Kang, J., Lee, H. R., Kim, S. W., Hyun, J., \& Park, I. K. (2015). Larvicidal and acetylcholinesterase inhibitory activities of apiaceae plant essential oils and their constituents against Aedes albopictus and formulation development. Journal of Agricultural and Food Chemistry, 63(45), 9977-9986. https://doi.org/10.1021/acs.jafc.5b03586 
Shaalan, E. A. S., Canyon, D., Younes, M. W. F., Abdel-Wahab, H., \& Mansour, A. H. (2005). A review of botanical phytochemicals with mosquitocidal potential. In Environment International (Vol. 31, Issue 8, pp. 1149-1166). Elsevier Ltd. https://doi.org/10.1016/j.envint.2005.03.003

Srivastava, S., Gupta, M. M., Prajapati, V., Tripathi, A. K., \& Kumar, S. (2001). Insecticidal activity of myristicin from Piper mullesua. Pharmaceutical Biology, 39(3), 226-229. https://doi.org/10.1076/phbi.39.3.226.5933

Sukumar, K., Perich, M. J., \& Boobar, L. R. (1991). Botanical derivatives in mosquito control: A review. Journal of the American Mosquito Control Association, 7(2), 210-237.

Suratman, S., Edwards, J. W., \& Babina, K. (2015). Organophosphate pesticides exposure among farmworkers: Pathways and risk of adverse health effects. Reviews on Environmental Health, 30(1), 65-79. https://doi. org/10.1515/REVEH-2014-0072

Tuekaew, J., Siriwatanametanon, N., Wongkrajang, Y., Temsiririrkkul, R., \& Jantan, I. (2014). Evaluation of the antioxidant activities of Ya-hom Intajak, a Thai herbal formulation, and its component plants. Tropical Journal of Pharmaceutical Research, 13(9), 1477-1485. https://doi.org/10.4314/tjpr.v13i9.14

Uebel, T., Hermes, L., Haupenthal, S., Müller, L., \& Esselen, M. (2020). $\alpha$-Asarone, $\beta$-asarone, and $\gamma$-asarone: Current status of toxicological evaluation. Journal of Applied Toxicology, 41(8), 1166-1179. https://doi. org/10.1002/jat.4112

Ugusman, A., Zakaria, Z., Hui, C. K., Nordin, N. A. M. M., \& Mahdy, Z. A. (2012). Flavonoids of Piper sarmentosum and its cytoprotective effects against oxidative stress. EXCLI Journal, 11, 705-714. https:// doi.org/10.17877/DE290R-10356

Vimaladevi, S., Mahesh, A., Dhayanithi, B., \& Karthikeyan, N. (2012). Mosquito larvicidal efficacy of phenolic acids of seaweed Chaetomorpha antennina (Bory) Kuetz. against Aedes aegypti. Biologia, 67(1), 212216. https://doi.org/10.2478/s11756-011-0152-9

Wang, Y., Lv, L., Yu, Y., Yang, G., Xu, Z., Wang, Q., \& Cai, L. (2017). Single and joint toxic effects of five selected pesticides on the early life stages of zebrafish (Denio rerio). Chemosphere, 170, 61-67. https:// doi.org/10.1016/j.chemosphere.2016.12.025.

World Health Organization. (2005). Guidelines for laboratory and field testing of mosquito larvicides. World Health Organization.

World Health Organization. (2021). Dengue and severe dengue. World Health Organization.

Zaidan, U. H., Hamid, S. N. M., Yusof, M. F. M., Ahmad, S., Gani, S. S. A., \& Shamsi, S. (2018). Chemical evaluation and antioxidant properties of extracts and essential oil from Stevia rebaudiana leaves. Malaysia Applied Biology, 47(2), 15-23.

Zaidan, U. H., Zen, N. I. M., Amran, N. A., Shamsi, S., \& Gani, S. S. A. (2019). Biochemical evaluation of phenolic compounds and steviol glycoside from Stevia rebaudiana extracts associated with in vitro antidiabetic potential. Biocatalysis and Agricultural Biotechnology, 18, Article 101049. https://doi. org/10.1016/j.bcab.2019.101049 
